\title{
Microfundamentos de Falência de Bancos Atacadistas: A Experiência Brasileira nos Anos 90
}

\author{
Michel Alexandre \\ Otaviano Canuto \\ José Maria da Silveira
}

\author{
Doutorando do IPE/USP \\ Professor da FEA/USP \\ Professor da Unicamp
}

\section{RESUMO}

$O$ artigo aborda a especificidade dos microfundamentos de falência de bancos atacadistas na experiência brasileira de meados da década dos 90. A hipótese testada é a de que os bancos atacadistas possuem microfundamentos de falência peculiares, já que suas características estruturais diferem substancialmente daquelas dos bancos varejistas. Caso esteja correta a suposição quanto à significância de tais diferenças, não poderá deixar de ser considerada pelos modelos de early warning aplicados ao caso brasileiro.

\section{PALAVRAS-CHAVE}

microfundamentos de falência bancária, crises bancárias, bancos atacadistas.

ABSTRACT

This paper approaches the microfoundations of failures presented by Brazilian wholesale banks along the banking crisis of the mid-90's. We test the hypothesis that wholesale banks share peculiar microfoundations of failure as compared to other banking branches, given some structural differences at least in the Brazilian case. In case of support by data to that hypothesis, early warning models as applied to Brazil shall take those features into consideration.

KEY WORDS microfoundations of banking failures, banking crises, wholesale banks.

JEL Classification

G2I 


\section{INTRODUÇÃO}

Nas duas últimas décadas, as crises bancárias tornaram-se fenômenos cada vez mais freqüentes. Segundo Claessens et al. (2001), entre 1980 e 1998 ocorreram 105 casos de crises bancárias sistêmicas. A maior parte delas (63) ocorreu nos anos 90. Trata-se de um índice expressivamente maior que o das três décadas anteriores.

Não há, na literatura econômica, um conceito definido de modo inequívoco para classificar uma crise bancária como sistêmica. Demirgüç-Kunt e Detragiache (1997) estabeleceram, com base nos estudos existentes, quatro fatores como os mais freqüentemente citados para caracterizar uma crise bancária sistêmica: a) taxas de ativos não realizáveis como proporção acima de $10 \%$ dos ativos totais; b) custo de reestruturação bancária acima de $2 \%$ do PIB; c) problemas bancários como resultado de uma nacionalização dos bancos em larga escala; e d) ocorrência de corrida aos bancos em grandes proporções e/ou de medidas emergenciais (como congelamento de depósitos, prolongados feriados bancários e garantias generalizadas sobre depósitos). Se há o cumprimento de pelo menos uma dessas condições, segundo o ponto de vista desses autores, a crise bancária pode ser considerada sistêmica.

A maioria dessas crises tem ocorrido em países emergentes. Segundo aqueles autores, dos 93 países que passaram por crises bancárias sistêmicas durante o período de 1980/98, apenas 5 eram desenvolvidos: Estados Unidos (1984 e 1991), Espanha (1985), Noruega (1987 e 1989), Suécia (1991) e Finlândia (1991 e 1993). Todavia, no estudo realizado com o objetivo de detectar a ocorrência de crises bancárias sistêmicas em uma amostra de 65 países que passaram por distúrbios em seus sistemas bancários entre 1980 e 1994, a freqüência relativa de crises bancárias sistêmicas nos países subdesenvolvidos (48\%) não ficou muito acima daquela dos países desenvolvidos (38\%). Portanto, ainda que o número de crises bancárias sistêmicas ocorridas em países subdesenvolvidos seja superior ao das acontecidas em países desenvolvidos, é discutível que a freqüência relativa das crises bancárias sistêmicas seja maior nos primeiros. 
Os estudos que procuram identificar os determinantes de ocorrência de crises bancárias normalmente os dividem entre os de caráter macroeconômico e de caráter microeconômico. Dentre as causas relacionadas a fatores macroeconômicos destacam-se: vulnerabilidade macroeconômica, explosão creditícia, liberalização financeira, forte presença do setor público no sistema bancário e regimes de taxas cambiais fixas. Por seu turno, os determinantes de crises bancárias de caráter microeconômico normalmente são localizados em problemas de má administração, agravados por práticas de maquiagem de balanços. ${ }^{1}$

O Brasil é um dos países que passaram por distúrbios em seu sistema bancário nos anos 90. Entre 1994 e 1996, dois bancos grandes (Nacional e Econômico) e vários outros menores tiveram sua liquidação decretada pelo Banco Central. Atribui-se a fragilização bancária brasileira desse período a fatores como perda das receitas inflacionárias com a estabilização a partir de 1994, a expansão creditícia acompanhada pelo acúmulo de créditos de má qualidade durante o segundo semestre de 1994 e o default mexicano em fins de 1994 e início de 1995.

Os modelos de early warning complementam a análise dos microdeterminantes de falência bancária. Esses estudos procuram identificar, dentre um determinado conjunto de indicadores microeconômicos bancários, quais foram relevantes na determinação das falências ocorridas. Os trabalhos de early warning aplicados à crise bancária brasileira de 1994/95 (ROCHA, 1999; JANOT, 2001) apontam como microderminantes relevantes, na ocorrência da mesma, fatores como baixa participação de captações em dólares na captação total, baixa rentabilidade, alta participação de ativos não-usuais sobre os ativos totais e elevado crescimento das captações.

Supõe-se, no entanto, que características estruturais de um determinado banco influenciem seus microdeterminantes de falência. A partir dessa premissa, espera-se que bancos atacadistas, por possuírem características es-

1 A respeito dos determinantes de crises bancárias, ver, por exemplo, os trabalhos de CANUTO \& LIMA (1999), DE JUAN (1996), GAVIN \& HAUSMANN (1996), GOLDSTEIN \& TURNER (1996), MIOTTI \& PLIHON (1999) e SACHS (1996). 
truturais peculiares, também possuam microdeterminantes de falência específicos. Portanto, espera-se que os microdeterminantes de falência de bancos atacadistas possam ser distintos daqueles aplicáveis ao sistema bancário como um todo.

Esse artigo trata da especificidade dos microfundamentos de falência dos bancos atacadistas nesta experiência brasileira de meados da década dos 90. A hipótese que se pretende testar aqui, a partir da crise bancária brasileira de 1994/95, é a de que os bancos atacadistas possuem microfundamentos de falência peculiares, já que suas características estruturais diferem substancialmente daquelas dos bancos varejistas.

Além desta introdução, o presente artigo divide-se em mais quatro seções. Na seção 1, faz-se uma caracterização geral da crise bancária brasileira de 1994/95. Na seção 2, serão apontados os resultados de alguns trabalhos de early warning aplicados ao caso brasileiro, de modo a identificar os microfundamentos de falência sugeridos para o caso do sistema bancário brasileiro. A terceira seção tratará das diferenças estruturais entre bancos varejistas e atacadistas. Por fim, na quarta seção será desenvolvido um modelo de early warning específico para bancos atacadistas brasileiros, usando as técnicas de análise de componentes principais (ACP) e logit, de modo a avaliar a hipótese da especificidade dos microfundamentos de falência dos bancos atacadistas.

\section{CARACTERIZAÇÃO GERAL DA CRISE BANCÁRIA BRASI- LEIRA DE 1994/95²}

Com a implantação do Plano Real em 1994 e a conseqüente perda das receitas inflacionárias, o sistema bancário brasileiro foi duramente abalado. Conforme tratado por Baer e Nazmi (2000), a inflação era favorável aos

2 Para alguns analistas, não chegou efetivamente a ocorrer uma crise bancária no Brasil no período 1994/95. Na visão de CARDIM DE CARVALHO (1996), por exemplo, os distúrbios pelos quais passaram os bancos brasileiros nesse período caracterizariam uma ameaça importante ou mesmo uma situação de estresse, mas não uma plena crise bancária. 
bancos sob três aspectos. Primeiro, permitia aos bancos obter grandes rendimentos (o chamado floating) mediante pagamento de uma taxa de juros real muito baixa ou até mesmo negativa sobre o excesso de depósitos que restava dos requerimentos de reserva. Segundo, ao reduzir o valor real dos passivos bancários, a inflação diminuía o risco de insolvência. Terceiro, adicionava liquidez ao sistema, ao tornar mais fácil aos tomadores de empréstimo pagar suas dívidas.

No entanto, ao mesmo tempo que o Plano Real prejudicou os bancos com a eliminação dos ganhos inflacionários, beneficiou-os com o aumento do PIB e do consumo. Favorecido pelo aumento do produto e dos salários reais, o consumo apresentou altas taxas de crescimento. $\mathrm{O}$ crescimento do PIB foi de 5,9\% em 1994 e de 4,2\% em 1995. O consumo, por sua vez, como proporção do PIB, passou de 77,5\% em 1994 para 79,5\% em 1995. Também houve, desse modo, um aumento na demanda por crédito bancário, cujo restabelecimento foi possível graças à estabilização inflacionária. Assim sendo, os bancos puderam obter ganhos consideráveis com operações de crédito que compensaram, parcialmente, a perda das receitas inflacionárias. De acordo com dados da Conjuntura Econômica, o crédito bancário para pessoas físicas cresceu mais de 180\% em 1994.

Ainda que benéfica no curto prazo, essa expansão das operações de crédito gerou problemas no longo prazo para o sistema bancário, por três razões. (BAER \& NAZMI, 2000) Primeiro, por terem se desenvolvido num regime de alta inflação que lhes proporcionava ganhos fáceis e inibia as operações de crédito, os bancos não estavam habituados a realizar decisões de crédito e análise de risco, novos aspectos tornados centrais no novo ambiente macroeconômico.

Segundo, a presença de risco moral, na forma de salvaguarda governamental e de métodos de supervisão ineficazes, não induzia a que os bancos fossem prudentes no desenvolvimento de suas operações de crédito. Essa salvaguarda governamental era implícita no caso dos bancos privados e explícita para os bancos públicos. 
Terceiro, tratando-se especificamente dos bancos públicos, houve excessivo direcionamento de crédito, por parte dos bancos estaduais, para o próprio setor público. Desde o retorno do País à democracia no início dos anos 80 , os bancos estatais já vinham emprestando grandes quantias a órgãos governamentais, empréstimos estes muitas vezes não pagos.

Segundo Von Doellinger (1991), os bancos estatais atuaram, na prática, como instrumentos de financiamento de déficit público. De acordo com dados do Banco Central, entre janeiro de 1995 e julho de 1996 as operações de crédito dos bancos estaduais cresceram R \$ 3,6 bilhões. Desse montante, apenas R \$ 900 milhões foram para o setor privado e os restantes R \$ 2,7 bilhões foram para o setor público. Os bancos privados, ao contrário, procuraram afastar seus empréstimos do setor público. Como atestam Loyola et al. (1997), "parcela expressiva dos Estados não vinha pagando essas dividas" e, portanto, "a expansão do saldo dos empréstimos dos bancos estaduais foi acompanbada por uma piora nos indicadores de liquidez desses bancos." Aprofundou-se, assim, o já mencionado comprometimento dos empréstimos dos bancos estaduais com o setor público.

Com o câmbio valorizado a partir do início do Plano Real e a redução gradual nas tarifas, a maior parte da expansão do consumo direcionou-se para as importações, resultando em grande déficit na conta de transações correntes. Esse valor, de US\$ 592 milhões em 1993, atingiu US\$ 1,7 bilhão em 1994 e quase ultrapassou US\$ 18 bilhões em 1995.

Esse déficit era financiado inicialmente com fortes entradas de capital externo. Contudo, com a crise do México e o chamado "Efeito Tequila" no final de 1994 e início de 1995, o fluxo de capitais se reverteu. Segundo dados do Banco Central, o saldo da conta de capitais, de US\$ 14,3 bilhões em dezembro de 1994, passou para uma posição de US\$ 791 milhões em março de 1995.

Com a vigência do regime cambial brasileiro de bandas cambiais a partir de 1995, isso resultou em crise no balanço de pagamentos, aumento no custo de crédito e piora nas finanças bancárias, segundo Baer e Nazmi 
(2000). Para enfrentar o problema no balanço de pagamentos e manter a paridade da taxa de câmbio, à qual o Plano Real conferiu papel fundamental na estabilidade dos preços, o Banco Central aumentou sensivelmente a taxa de juros. Segundo dados do Banco Central, no final do primeiro trimestre de 1995 a taxa de juros de curto prazo (TR) chegou a níveis próximos de $70 \%$ ao mês.

O forte aumento dos juros, associado ao já mencionado fato de que os bancos, principalmente os públicos, expandiram seus empréstimos sem uma efetiva análise de risco, fragilizou o sistema bancário. De fato, os bancos tiveram grandes perdas com créditos de liquidação duvidosa, uma vez que boa parte de seus devedores tornou-se inadimplente. De acordo com dados do Banco Central, os créditos em atraso e em liquidação subiram de 3,8\% dos créditos totais em junho de 1994 para 10,3\% em dezembro de 1995.

Os bancos também reduziram sensivelmente suas operações de crédito, o que pode ser explicado parcialmente pelo problema de seleção adversa (STIGLITZ \& WEISS, 1981): sabendo que maiores juros atraem os tomadores de maior risco-retorno e afastam os de menor risco-retorno, os emprestadores, diante da possibilidade de aumento nos juros, podem preferir reduzir sua oferta de crédito a expandi-la. No caso brasileiro, a redução do crédito causou queda na atividade econômica, o que aprofundou ainda mais a crise bancária.

Portanto, ainda que os distúrbios pelos quais passou o sistema bancário brasileiro em meados dos anos 90 tenham sido desencadeados pela perda das receitas inflacionárias, foram agravados pela crise mexicana no início de 1995, a qual afetou negativamente a capacidade de pagamento dos tomadores de empréstimos bancários e aumentou a inadimplência. No caso específico dos bancos estaduais, também houve o excessivo direcionamento de empréstimos ao setor público, que já não vinha pagando suas dívidas com os bancos. 


\section{CRISE DO SISTEMA BANCÁRIO BRASILEIRO NOS ANOS 90: ASPECTOS MICROECONÔMICOS}

Na seção anterior, tratou-se a crise bancária brasileira de 1994-95 analisando seus determinantes macroeconômicos. Nesta seção, o objetivo é fazer uma caracterização geral de seus microfundamentos. Pretende-se responder à seguinte questão: dado um certo conjunto de fatores macroeconômicos que fragilizaram o sistema bancário, quais elementos determinaram, do ponto de vista microeconômico, a falência e a sobrevivência de certos bancos? Qual é o perfil - traçado a partir de microfundamentos - dos bancos que sucumbiram perante a crise e dos que resistiram a ela? Para tanto, resumimos aqui os resultados de dois estudos: o de Janot (2001) e o de Rocha (1999).

Janot (2001) utiliza dois modelos para a identificação dos microfundamentos de falência bancária no Brasil: o modelo logit e o modelo de risco proporcional de $\mathrm{Cox}^{3}$. A amostra utilizada nesse trabalho foi formada pelos 21 bancos que sofreram intervenção ou foram liquidados pelo Banco Central nos anos de 1995 e 1996, além de um grupo de 40 bancos solventes privados de grande porte, de acordo com o critério de participação do ativo do banco no total de ativos do sistema bancário. Cada um desses bancos possuía uma participação superior a $0,2 \%$ no total de ativos do sistema bancário em 31/12/1994.

Como possíveis previsores de falência bancária, foram testados os 68 indicadores econômico-financeiros que compõem o INDCON (Indicadores Econômico-financeiros de Instituições sob Acompanhamento e Controle do Banco Central do Brasil), um sistema montado pelo Banco Central do Brasil para avaliar a situação econômico-financeira das instituições sob seu controle. Esses indicadores estão divididos em cinco grupos gerais, criados

3 Enquanto o modelo logit estima coeficientes de variáveis independentes que determinam a ocorrência de um determinado evento, o modelo de risco proporcional de Cox estima também a probabilidade de que esses eventos ocorram dentro de t períodos de tempo por meio da chamada função sobrevivência (survivor function). 
em função da estrutura de capital, dos ativos, da rentabilidade, da eficiência gerencial e da liquidez dos bancos, dando origem à sigla CAREL. Correspondem a uma versão adaptada da tradicional metodologia CAMEL.

Como o número de bancos da amostra era pequeno em relação ao número de indicadores, foi necessário adotar algum critério para se excluir os indicadores menos relevantes. Primeiro, foi calculada a média de cada indicador separadamente para os bancos que faliram e os que não faliram. Em seguida, o autor verificou, por meio do teste $\mathrm{T}$, se as médias dos indicadores para cada um dos grupos de bancos eram estatisticamente iguais, ao nível de significância de $5 \%$. Para tanto, testou $\mathrm{H}_{0}: \mu \mathrm{l}=\mu 2$ contra $\mathrm{H}_{\mathrm{A}}: \mu \mathrm{l}$ $\neq \mu 2$, onde $\mu 1$ e $\mu 2$ são as médias do indicador correspondentes ao grupo de bancos solventes e insolventes, respectivamente. Quando o teste não refutava a hipótese nula para um certo indicador, o mesmo era excluído, pois não discriminava bem os dois grupos de bancos. Ao final, foram utilizados 29 - dos 68 - indicadores que permitiram rejeitar a hipótese nula ao nível de $5 \%$.

A partir do modelo logit, o método de Backward Stepwise com a estatística Wald selecionou três indicadores como previsores de insolvência bancária:

- Participação das captações em moeda estrangeira dentro das exigibilidades (CAPDOLAR);

- Participação das operações ativas não usuais na carteira ativa (PARTNUSU). Foram considerados como ativos não usuais aquelas operações não ligadas diretamente aos objetivos sociais da instituição, tais como: bens não destinados a uso, certificados de privatização, despesas antecipadas e outros créditos.

- Participação de ativos de liquidez imediata nas operações ativas usuais (PARTATIM).

A Tabela 1, a seguir, apresenta os coeficientes, o desvio padrão e o nível de significância para cada um dos três indicadores e para a constante: 
TABELA 1 - RESULTADOS DE ESTIMAÇÃO DO MODELO LOGIT

\begin{tabular}{lccc}
\hline Indicador & Coeficiente & Desvio Padrão & Nível de Sign. \\
\hline CAPDOLAR & $-0,1897$ & 0,0590 & 0,0013 \\
PARTATIM & $-0,1071$ & 0,0453 & 0,0181 \\
PARTNUSU & 0,4423 & 0,2058 & 0,0316 \\
Constante & 3,6200 & 1,6948 & 0,0327 \\
\hline
\end{tabular}

Fonte: JANOT (2001).

Aplicado aos bancos da amostra, o modelo logit mostrou-se bastante satisfatório. Se a probabilidade estimada de insolvência do banco for superior a 0,5 , o modelo considera que esse banco se tornará insolvente nos próximos dois anos, classificando-o como solvente na situação contrária. O modelo logit apresentou um alto porcentual de acerto (91,80\%), classificando corretamente $95 \%$ dos bancos solventes da amostra e $85,71 \%$ dos bancos insolventes, como mostra a Tabela 2, a seguir.

TABELA 2 - APLICAÇÃO DO MODELO LOGIT AOS BANCOS DA AMOSTRA

\begin{tabular}{|c|c|c|c|}
\hline \multirow[t]{2}{*}{ Situação Real do Banco } & \multicolumn{2}{|c|}{ Situação Estimada do Banco } & \multirow{2}{*}{$\begin{array}{l}\text { Porcentual de Acerto da } \\
\text { Classificação }\end{array}$} \\
\hline & Solvente & Insolvente & \\
\hline Solvente & 38 & 2 & $95,00 \%$ \\
\hline Insolvente & 3 & 18 & $85,71 \%$ \\
\hline
\end{tabular}

Fonte: JANOT (2001).

Já o modelo de risco proporcional de Cox, utilizando o método Forward Stepwise, selecionou as seguintes variáveis como relevantes na previsão de falência bancária:

- Custo administrativo médio mensal do ativo total no semestre (CUSADMED); 
- Participação dos ativos de realização imediata nas operações ativas usuais (PARTATIM);

- Participação das captações em moeda estrangeira nas exigibilidades (CAPDOLAR).

Vale notar que esses dois últimos indicadores também foram selecionados pelo modelo logit. A Tabela 3 mostra o coeficiente, o desvio padrão e o nível de significância para cada um dos indicadores:

TABELA 3 - RESULTADOS DE ESTIMAÇÃO DO MODELO DE COX

\begin{tabular}{lrrc}
\hline Indicador: & Coeficiente: & Desvio Padrão: & Nível de Sign: \\
\hline CAPDOLAR & $-0,0788$ & 0,0306 & 0,0099 \\
PARTATIM & $-0,0372$ & 0,0156 & 0,0173 \\
CUSADMED & 0,6929 & 0,2125 & 0,0011 \\
\hline
\end{tabular}

Fonte: JANOT (2001).

Foi estimada a probabilidade de que um banco sobreviva mais do que $t$ meses. Se a probabilidade estimada de sobrevivência do banco for inferior a 0,5 - o valor de corte adotado -, o modelo o classifica como insolvente, pondo-o como solvente em caso contrário. Foram estimadas as probabilidades de sobrevivência para os bancos da amostra dentro de 6, 12, 18 e 24 meses e em seguida foram calculados os erros tipo I e tipo II. O erro tipo I seria classificar um banco que quebrou como uma não-quebra, por estar acima do nível de corte. Por seu turno, o erro tipo II seria classificar um banco que não quebrou como uma quebra. ${ }^{4}$ Os resultados estão na Tabela 4.

4 ROCHA (1999) mostra que uma porcentagem elevada de Erro Tipo I teria consequiências práticas sobre a confiabilidade dos sistemas de early warning, por estes não preverem adequadamente possibilidade de quebra de um banco. Já o Erro Tipo II, ainda que menos importante, poderia induzir movimentos de agentes preocupados com a situação de um determinado banco ou de um conjunto de bancos em situação pré-falimentar. 


\section{TABELA 4 - CLASSIFICAÇÃO DOS BANCOS PELO MODELO DE COX}

\begin{tabular}{cccc}
\hline Meses: & Bem Classificado: & Erro Tipo I: & Erro Tipo II: \\
\hline 6 & $78,3 \%$ & $1,7 \%$ & $20 \%$ \\
12 & $73,3 \%$ & - & $26,7 \%$ \\
18 & $68,3 \%$ & - & $31,7 \%$ \\
24 & $66,7 \%$ & - & $33,3 \%$ \\
\hline
\end{tabular}

Fonte: JANOT (2001)

Os seguintes indicadores foram apontados, por Janot (2001), como importantes microfundamentos de falência dos bancos brasileiros em 1994/ 95: altos custos administrativos, baixa captação em dólares, baixa participação de ativos de liquidez imediata nos ativos totais e alta participação de operações ativas não usuais na carteira ativa.

Rocha (1999) trabalhou apenas com o modelo de risco proporcional de Cox. ${ }^{5} \mathrm{~A}$ amostra foi formada por 15 bancos privados declarados insolventes no período de julho de 1994 a dezembro de 1995, em conjunto com os 17 maiores bancos privados do País. Os bancos públicos foram excluídos da amostra, uma vez que as razões de falência dos mesmos estariam mais ligadas a questôes fiscais do que financeiras. ${ }^{6}$ Foram utilizados dois conjuntos de dados. O primeiro, chamado de conjunto de um ano atrás, foi formado pelos 26 indicadores em 31 de dezembro do ano anterior à insolvência para cada um dos bancos. O outro, chamado de conjunto de dados de dois anos atrás, foi composto pelos mesmos indicadores em 31 de dezembro de dois anos antes da falência dos bancos. Vários modelos de Cox alternativos foram testados para encontrar o conjunto de indicadores que melhor explicasse as falências bancárias. Um resumo das estimações, tanto para o conjunto de um ano quanto para o conjunto de dois anos atrás, está nas tabelas seguintes.

5 Vide seção 2 do texto da autora para apresentação de um resumo da metodologia.

6 ROCHA (1999) parte de 26 indicadores financeiros extraídos do Manual de Análise da Austin Asis. 


\section{TABELA 5 - RESUMO DOS RESULTADOS DO MODELO DE COX}

\begin{tabular}{llccr}
\hline $\begin{array}{l}\text { I.Conjunto de dados } \\
\text { de um ano atrás }\end{array}$ & Variável: & Coeficiente: & $\begin{array}{c}\text { Nível de } \\
\text { Probabilidade: }\end{array}$ & Erro-Padrão: \\
\hline & Margem Líquida & $-0,209$ & 0,00283 & 0,0702 \\
$\begin{array}{l}\text { II. Conjunto de dados } \\
\text { de dois anos atrás }\end{array}$ & Variável: & Coeficiente: & $\begin{array}{c}\text { Nível de } \\
\text { Probabilidade: }\end{array}$ & Erro-Padrão: \\
& $\begin{array}{l}\text { Alavancagem } \\
\text { Margem Líquida }\end{array}$ & 0,001391 & 0,0163 & 0,00058 \\
& $\begin{array}{l}\text { Captações } \\
\text { (Cresc.) }\end{array}$ & 0,000309 & 0,0283 & 0,14162 \\
& & & 0,0317 & 0,00014 \\
\hline
\end{tabular}

Fonte: ROCHA (1999).

As variáveis apresentadas na Tabela 5 estão relacionadas à probabilidade de falência do banco. Por exemplo, para o conjunto de dados dois anos atrás, quanto maior a alavancagem, menor a margem líquida e maior a captação total, maior a probabilidade de falência do banco. Portanto, neste trabalho todas as variáveis apresentaram perfis de falência esperados intuitivamente.

Rocha (1999), no entanto, aponta que a variável alavancagem por ela usada foi, na verdade, uma variável composta, ou seja, uma variável binária, para os bancos pequenos, combinada com a alavancagem original (captações/patrimônio líquido). Observa também que, como os bancos pequenos tendem a captar usando instrumentos de maior risco, o porte dos bancos teve influência no resultado obtido. Conclui que o importante é a composição da captação e não sua relação com o patrimônio líquido. Dessa forma, uma maior alavancagem seria nociva aos bancos pequenos, por envolver maior risco na captação.

Caminhando na direção de construir um modelo de early warning, Rocha estimou a probabilidade de um determinado banco sobreviver mais do que $t$ períodos. Para o conjunto de dados um ano atrás, foi calculada a probabilidade de um banco sobreviver mais do que $t$ meses, onde $0<t \leq 12$. No caso do conjunto de dados para dois anos atrás, $12<t \leq 24$. Para o conjun- 
to de dados de um ano atrás, a probabilidade média estimada de um banco saudável sobreviver mais do que um número qualquer de meses entre 0 e 12 seria de $96 \%$. No caso de um banco não-saudável, esse valor muda para aproximadamente $30 \%$.

Para o conjunto de dados dois anos atrás, a probabilidade média estimada de um banco saudável sobreviver mais do que um certo número de meses entre 12 e 24 seria de $81 \%$, enquanto que para um banco nãosaudável esse valor seria de $3 \%$. Tal como no trabalho de Janot, citado acima, a probabilidade estimada de um banco sobreviver mais do que $t$ meses é comparada com um valor de corte. Se esta probabilidade estiver abaixo do valor de corte, o banco é declarado como uma provável quebra. Caso contrário, esse banco será classificado como falência improvável.

Rocha (1999) utiliza alguns pontos de referência para a análise de sobrevivência dos bancos. Assim, para o conjunto de dados de um ano atrás, a análise é feita para probabilidades de sobrevivência previstas para 6 e 12 meses; e para o conjunto de dados dois anos atrás, esses valores são de 18 e 24 meses. Nos dois casos, a proporção dos bancos que não faliram na amostra é usada para determinar os valores de corte. Assim, a probabilidade de um banco sobreviver mais do que 6 e 12 (18 e 24) meses, quando o conjunto de um ano (dois anos) atrás é considerado, aparece aproximadamente como de $97 \%$ e $47 \%$, respectivamente.

A fixação desses pontos de corte permitiu a obtenção dos erros tipo I e II. A Tabela 6, a seguir, mostra os números de erros tipo I e II cometidos para o conjunto de dados de um ano e também para os de dois anos atrás: os erros tipo I não chegam a $30 \%$ e os de tipo II quase chegam a $40 \%$. No entanto, é importante notar que a maior parte dos erros tipo II cometidos refere-se a bancos que faliram algum tempo depois.

Rocha (1999, p. 149) fornece uma informação adicional: "no caso do conjunto de dados de um ano atrás, dos 10 bancos que não faliram dentro dos 6 meses, 9 faliram entre 6 e 12 meses. Assim, apenas um erro tipo II foi cometido." Prossegue, mostrando que "no conjunto de dados dois anos atrás, dos 12 bancos que não faliram dentro dos 18 meses, 11 faliram entre 18 e 24 meses. Desse modo, também nesse caso, apenas um erro tipo II foi cometido." 
TABELA 6 - ERROS TIPO I E II DE ACORDO COM O MODELO DE COX

\begin{tabular}{lccc}
\hline Conjunto de dados de um ano atrás & $\begin{array}{c}\text { Horizonte de tempo } \\
\text { (meses): }\end{array}$ & Erro tipo I: & Erro tipo II: \\
\hline 6 & $0(0 \%)$ & $10(32 \%)$ \\
\hline Conjunto de Dados de dois anos atrás & $\begin{array}{c}\text { Horizonte de tempo } \\
\text { (meses): }\end{array}$ & Erro tipo I: & Erro tipo II: \\
\hline 18 & $0(0 \%)$ & $12(39 \%)$ \\
& 24 & $3(20 \%)$ & $2(12 \%)$ \\
\hline
\end{tabular}

Fonte: ROCHA (1999).

Percebe-se, portanto, como o modelo de risco proporcional de Cox mostrou-se altamente eficaz nesse estudo. Além de declarar o conjunto de variáveis relacionadas à probabilidade de falência de um banco com nível alto de significância, o modelo foi preciso em classificar um banco como tendo problemas antes de sua insolvência. A autora observa que os casos de erro de previsão são importante objeto de pesquisa, pois podem explicar o porquê das falhas do modelo, dando base a novas formulações.

Em suma, de acordo com os trabalhos aqui apresentados, os microfundamentos destacados na determinação das falências bancárias no Brasil nos anos de 1995 e 1996 foram os seguintes:

- Baixa captação em moeda estrangeira com relação às demais fontes de captação (estrutura);

- Elevada alavancagem (no caso dos bancos pequenos) (estrutura);

- Baixa participação dos ativos de liquidez imediata no total das operações ativas usuais (solvência);

- Elevada aplicação em ativos não ligados aos objetivos sociais da instituição (qualidade de ativos);

- Elevados custos administrativos, inclusive encargos com pessoal (custos); 
- Baixa margem líquida (resultado líquido/receita da intermediação financeira) (rentabilidade); e

- Elevado crescimento das captações (crescimento).

Tais indicadores podem ser considerados importantes na explicação das falências bancárias que ocorreram no Brasil após o Plano Real. Os testes indicaram alto poder explicativo dessas variáveis e os modelos desenvolvidos pelos trabalhos aqui apresentados mostraram-se altamente eficazes na classificação dos bancos como solventes e insolventes, usando esses indicadores.

Pelo menos no caso das captações em moeda estrangeira, a eficácia do indicador como previsor de falência bancária está associada à conjuntura econômica vigente na época pós-Real. Como aponta Janot (2001), nessa época vigorava um amplo diferencial entre as taxas de juros praticadas internamente e no exterior, bem como uma desvalorização do câmbio apenas lenta e gradual durante os dois anos que se seguiram à implantação do Real. Assim, os bancos que fizeram maiores captações em moeda estrangeira beneficiaram-se com taxas de juros mais favoráveis e uma gradual valorização de seus recursos captados. Outros indicadores (altos custos, baixa liquidez dos ativos, aplicações em ativos não usuais, baixa rentabilidade e alta alavancagem, no caso dos bancos pequenos) são intuitivamente associados a futuros problemas para o banco. Por fim, um elevado crescimento das captações demonstrava a pressão que o banco estava exercendo sobre o mercado, em busca de recursos, constituindo-se em um claro sinal de que o mesmo passava por dificuldades.

\section{BANCOS VAREJISTAS E ATACADISTAS: DIFERENÇAS ES- TRUTURAIS}

$\mathrm{Na}$ seção anterior, foram apontados os microfundamentos de falência do sistema bancário brasileiro em sua crise de 1994/95. A hipótese que se pretende testar aqui, no entanto, é que os microfundamentos de falência dos bancos atacadistas brasileiros na crise de 1994/95 diferem significati- 
vamente desse padrão, dadas as suas características estruturais peculiares. Convém, portanto, identificar tais diferenças estruturais entre bancos atacadistas e varejistas.

Costa e Gonçalves (1997) distinguem o perfil de cada um dos grupos a partir da análise das características de uma amostra de quatro bancos varejistas (Bradesco, Itaú, Real e Unibanco) e quatro atacadistas (BBA Creditanstalt, Bozano Simonsen, Chase Manhattan e Multiplic). Os dados estudados referem-se a dezembro de 1996.

Os bancos varejistas apresentam um elevado número de correntistas, sendo as contas de baixo volume financeiro. Os quatro bancos varejistas da amostra somam 14,2 milhões de clientes e um total de R \$ 39,5 bilhões de depósitos, possuindo vasta rede de agências bancárias, com elevado número de funcionários. No caso da amostra aqui utilizada, o número de postos de atendimento chega a oito mil, com mais de 119 mil funcionários. Por sua vez, os bancos atacadistas operam com um menor número de clientes e agências, possuindo um volume financeiro maior por cliente, com os quatro bancos atacadistas da amostra somando apenas 12 agências cada.

Quanto à rentabilidade, os bancos varejistas têm uma relação lucro por agência relativamente baixa. Para os quatro bancos varejistas da amostra, esse valor foi de R $\$ 255$ mil. Os bancos atacadistas, ao contrário, possuem um lucro por agência muito maior, situando-se esse valor em R 42 milhôes para os bancos atacadistas da amostra.

Devido ao grande número de agências e funcionários, os bancos varejistas possuem elevadas despesas administrativas e com pessoal, o que fica evidente pelo dado que mostra que os quatro bancos da amostra comprometeram, em média, $48,6 \%$ de sua receita de intermediação financeira com tais despesas. Os bancos atacadistas, com uma estrutura operacional muito menor, comprometeram, no caso dos bancos da amostra, apenas 14,91\% de sua receita com despesas administrativas e de pessoal.

Os bancos varejistas, devido à estrutura operacional maior, possuem uma elevada imobilização do patrimônio líquido: em torno de $21 \%$ para os 
bancos da amostra, porcentual bem distante daquele encontrado na amostra para os bancos atacadistas, os quais possuem uma imobilização do patrimônio líquido de $2 \%$, dado coerente com a expectativa acerca desse tipo de banco.

As principais fontes de receitas dos bancos varejistas são as operações de crédito e a prestação de serviços bancários. Durante o período de alta inflação, no entanto, o floating era a principal fonte de lucro dos varejistas, devido ao elevado volume de depósitos a vista. Os bancos atacadistas, por sua vez, mesclam atividades de crédito e de administração de recursos com operações típicas de bancos de investimento (operaçôes de underwriting, fusões e aquisições, mercado de capitais e outras atividades ligadas à corporate finance). A principal fonte de captação dos bancos varejistas são os depósitos a vista. Para os quatro bancos da mostra, essa rubrica respondeu por 26,91\% dos recursos captados, seguida pelos depósitos a prazo (11,48\%). Os bancos atacadistas, por sua vez, concentram sua captação de recursos nas operaçóes de mercado aberto. No caso dos bancos da amostra, o comprometimento foi de $24,03 \%$ de suas captações com essa rubrica. Outras fontes importantes foram os depósitos interfinanceiros $(12,38 \%)$ e os depósitos a prazo (11,06\%).

Já no que se refere à estrutura ativa, as operaçóes de crédito constituem a principal aplicação dos bancos varejistas: no caso dos bancos da amostra, $31,48 \%$ do total do ativo. Para os bancos atacadistas, por seu lado, a maior parte do ativo é composta pelas aplicaçóes interfinanceiras. Os bancos da amostra aplicaram $30,08 \%$ de seus ativos nessa rubrica, contra $16,74 \%$ das operações de crédito. $\mathrm{O}$ único banco que fugiu a esse padrão foi o $\mathrm{BBA}$, cuja rubrica predominante no ativo foi a de títulos e valores mobiliários.

Portanto, as diferenças entre bancos varejistas e atacadistas podem ser divididas em quatro grupos: número de agências e clientes, captações, aplicações e fontes de receitas, conforme resumo no Quadro 1 a seguir: 


\section{QUADRO 1 - DIFERENÇAS ENTRE BANCOS VAREJISTAS E ATA- CADISTAS}

\begin{tabular}{|lll|}
\hline Característica: & \multicolumn{1}{|c|}{ Varejistas: } & \multicolumn{1}{c|}{ Atacadistas: } \\
\hline $\begin{array}{l}N^{\circ} \text { de Agências e } \\
\text { Clientes: }\end{array}$ & $\begin{array}{l}\text { Alto. Implicações: baixa relação } \\
\text { lucro/agência, altos custos } \\
\text { administrativos e alta imobilização do } \\
\text { capital }\end{array}$ & $\begin{array}{l}\text { Baixo. Implicações: alta relação } \\
\text { lucro/agência, baixos custos } \\
\text { administrativos e baixa imobilização do } \\
\text { capital }\end{array}$ \\
Aplicações: & Operações de Crédito & Aplicações Interfinanceiras \\
Captações: & $\begin{array}{l}\text { Depósitos de Poupança e Depósitos } \\
\text { a Prazo }\end{array}$ & $\begin{array}{l}\text { Operações de Mercado Aberto, Depósito } \\
\text { Interfinanceiros e a Prazo }\end{array}$ \\
Fontes de Receita: & Operações de Crédito e Prestação de & $\begin{array}{l}\text { Operações de Crédito, Administração de } \\
\text { Recursos, Atividades Típicas de Bancos } \\
\text { de Investimento }\end{array}$ \\
& Serviços Bancários & \\
\hline
\end{tabular}

\section{UM MODELO DE EARLY WARNING PARA BANCOS ATA- CADISTAS}

Nesta seção será desenvolvido um modelo de early warning especificamente para bancos atacadistas brasileiros. ${ }^{7} \mathrm{O}$ objetivo é comparar os resultados aqui obtidos com aqueles apresentados na seção 2 , para se tentar concluir a respeito da especificidade ou não dos microfundamentos de falência dos bancos atacadistas. Antes de aplicar o modelo logit, com o objetivo de estimar os indicadores que melhor explicam o risco (probabilidade) de falência de bancos atacadistas, consideramos de interesse realizar uma análise exploratória com base nos indicadores obtidos no $\mathrm{Ma}$ nual de Análise da Austin Asis, com dados referentes a junho de 1994. A amostra intencional é formada por um conjunto de 15 bancos atacadistas que sofreram liquidação ordinária ou extrajudicial por parte do Banco

7 Atendendo a sugestões feitas pela Profa. Fabiana Rocha sobre o trabalho de Alexandre (2001), os modelos que serão apresentados neste item foram testados com a inclusão de uma amostra de 15 bancos varejistas, dos quais 10 mantêm-se solventes. Os resultados obtidos não nos permitiram segregar os bancos varejistas solventes dos insolventes e, menos ainda, diferenciar os fatores determinantes da falência de bancos atacadistas daqueles determinantes dos varejistas. Neste sentido, o trabalho optou por circunscrever-se à investigação do comportamento dos bancos atacadistas. 
Central entre julho de 1994 e dezembro de 1996. Para efeito de comparação, trabalhamos também com um grupo formado por 33 bancos atacadistas que se mantiveram saudáveis (ver Anexo I para os bancos incluídos no estudo e suas respectivas siglas).

O uso da Análise dos Componentes Principais (ACP) visou identificar os indicadores responsáveis pelo comportamento diferencial dos bancos em relação a um conjunto de 11 indicadores entre os 26 mencionados. Esta seleção de indicadores baseou-se na análise apresentada nas seções anteriores do trabalho, nas características dos bancos atacadistas e na análise dos resultados preliminares da aplicação da $\mathrm{ACP}$ ao conjunto original. De fato, buscamos adequar o método à disponibilidade de dados sobre bancos atacadistas e ao manejo adequado da técnica, inclusive para testar se os resultados eram realmente robustos.

Mantivemos os indicadores segundo a classificação funcional referente aos microfundamentos bancários: adequação do capital; qualidade dos ativos; solvência; custos; rentabilidade; e crescimento (ver Quadro 2 abaixo, para a distribuição das variáveis utilizadas segundo os itens de classificação dos indicadores $\left.{ }^{8}\right)$.

A aplicação do método para as 11 variáveis e para as 48 bancos atacadistas - falidos e saudáveis - mostrou que o primeiro eixo é responsável por 30,66\% da variabilidade e que os 5 primeiros eixos explicam $83,65 \%$ da variação total, um resultado que se torna aceitável na medida em que se encontra uma justificativa clara para cada um deles em termos dos microfundamentos mencionados ao longo do texto. ${ }^{9}$ A suspeita de que alguns outliers poderiam estar interferindo no resultado, em razão de sua grande contribuição à inércia (variância), não se confirmou e os resultados mostram-se robustos

8 Para uma discussão aprofundada de cada variável e seu papel nos modelos de early warning, ver ALEXANDRE (2001).

9 O método utiliza variáveis normalizadas para evitar efeitos indesejáveis associados às dimensões das variáveis. O software utilizado foi o WINSPAD3.0. Este método apresenta algumas diferenças em relação ao utilizado pelo SAS ou STATISTICA, como mostram KAGEYAMA \& SILVEIRA (1997). O WINSPAD3.0 deixa os componentes com média zero e variância igual ao autovalor, o que valoriza o primeiro eixo fatorial. Usando as técnicas de identificação do número de eixos a reter, os resultados indicaram que a maior distância em termos de autovalor após a diagonalização da matriz de variâncias e covariâncias está entre $5^{\circ}$ e o $6^{\circ}$ eixos. 
em relação à interpretação observada com a amostra completa. (Ver no Anexo II alguns comentários sobre os bancos considerados outliers na ACP e sua relação com os indicadores de falência dos bancos atacadistas).

QUADRO 2 - INDICADORES ECONÔMICO-FINANCEIROS

\begin{tabular}{|c|c|c|}
\hline Indicador: & Significado: & Sigla: \\
\hline \multicolumn{3}{|l|}{ Adequação do Capital: } \\
\hline - Capitalização & Patrimônio Líquido/Captação Total & CAPT \\
\hline - Imobilização Própria & $\begin{array}{l}\text { (Ativo Permanente - Imobilizado de } \\
\text { Arredamento)/Patrimônio Líquido }\end{array}$ & IMPR \\
\hline - Imobilização Total & $\begin{array}{l}\text { (Ativo Permanente - Imobilizado de } \\
\text { Arredamento)/(Patrimônio Líquido + Exigível a LP) }\end{array}$ & IMTO \\
\hline - Capital de Giro & $\begin{array}{l}\text { (Patrimônio Líquido - Ativo Permanente)/Patr. } \\
\text { Líquido }\end{array}$ & KGIR \\
\hline \multicolumn{3}{|l|}{ Solvência: } \\
\hline - Encaixe & Disponibilidades/ Depósitos a vista & ENCX \\
\hline - Cobertura Voluntária & Disponibilidades/Passivo Real & covo \\
\hline - Solvência Corrente & Ativo Circulante Real/ Passivo Circulante Real & SOCO \\
\hline \multicolumn{3}{|l|}{ Qualidade de Ativos: } \\
\hline - Inadimplência & $\begin{array}{l}\text { Operações de Crédito de Liquidação Duvidosa/ Op, } \\
\text { Créd. }\end{array}$ & INDP \\
\hline - Provisionamento & Provisões de Créd, para Liq, Duvidosa/ Op, Créd. & PROV \\
\hline - Cobertura c/ Prov. & Prov. Cred. Liq. Duvidosa/ Oper .Cred. Liq. Duvidosa & COPR \\
\hline $\begin{array}{l}\text { - Comprometimento } \\
\text { Custos: }\end{array}$ & Oper. Cred. Liq. Duvidosa/ Patrimônio Líquido & COMP \\
\hline - Intermediação & $\begin{array}{l}\text { Despesa da Intermediação Financeira/ Captação } \\
\text { Total }\end{array}$ & CINT \\
\hline - Pessoal & Despesas c/ Pessoal/ Captação Total & CPES \\
\hline - Administrativo & Despesas Administrativas/ Captação Total & CADM \\
\hline - Total & Despesa Total/ Captação Total & СТОТ \\
\hline \multicolumn{3}{|l|}{ Rentabilidade: } \\
\hline - Geração de Rendas & $\begin{array}{l}\text { Receitas da Intermediação Financeira/ Aplicação } \\
\text { Total }\end{array}$ & GERE \\
\hline - Margem Bruta & Resultado Bruto da Interm. Fin./ Rec. Interm. Fin. & MGBR \\
\hline - Margem Operacional & Resultado Operacional/ Rec. Interm. Fin. & MGOP \\
\hline - Margem Líquida & Lucro Líquido/ Rec. Interm. Fin. & MGLQ \\
\hline - Rentab. do Patr. Liq. & Lucro Líquido/ Patrimônio Líquido & REPL \\
\hline \multicolumn{3}{|l|}{ Crescimento: } \\
\hline - Aplicações & Aplicações do último período/ Aplic. do per. anterior & CAPL \\
\hline - Captações & Captações do último período/ Capt. do per. anterior & CCAP \\
\hline - Rec. Interm. Fin. & $\begin{array}{l}\text { Rec. Interm. Fin. do último período/ RIF do per. } \\
\text { anterior }\end{array}$ & CRIF \\
\hline - Lucro Líquido & $\begin{array}{l}\text { Lucro Líq. Do último período/ Lucro Líq. do per. } \\
\text { anterior }\end{array}$ & CREL \\
\hline
\end{tabular}

Nota: Aplicações = Ativo Total - Relações Interdependências - Ativo Permanente. Captações = Passivo Total - Relações Interdependências - Patrimônio Líquido. As variáveis em destaque são as que foram utilizadas no modelo ACP. 
TABELA 7 - RESULTADOS DA ACP : COORDENADAS DOS EIXOS COORDENADAS/CORRELAÇÕES DAS VARLÁVEIS NOS CINCO PRIMEIROS EIXOS

\begin{tabular}{llllll}
\hline Variáveis & Eixo 1 & Eixo 2 & Eixo 3 & Eixo 4 & Eixo 5 \\
\hline IMPR & $-0,92$ & 0,13 & 0,10 & $-0,20$ & $-0,14$ \\
\hline IMTO & $-0,89$ & 0,07 & 0,08 & $-0,03$ & $-0,11$ \\
KGIR & 0,90 & $-0,14$ & $-0,10$ & 0,22 & 0,15 \\
SOCO & 0,38 & 0,25 & 0,82 & 0,17 & 0,08 \\
INDP & $-0,12$ & $-0,94$ & 0,04 & 0,16 & $-0,13$ \\
PROV & $-0,12$ & $-0,94$ & $-0,09$ & 0,01 & $-0,15$ \\
CADM & $-0,20$ & $-0,30$ & 0,78 & 0,32 & $-0,07$ \\
MGLQ & 0,55 & 0,14 & 0,27 & $-0,26$ & $-0,51$ \\
REPL & 0,56 & $-0,06$ & $-0,14$ & $-0,21$ & $-0,58$ \\
CAPL & $-0,31$ & 0,37 & $-0,09$ & 0,45 & $-0,54$ \\
\hline CREL & 0,00 & 0,18 & $-0,34$ & 0,77 & $-0,05$ \\
\hline
\end{tabular}

Fonte: Resultados próprios. Estão marcadas as variáveis que melhor representam a inércia de cada eixo.

A interpretação deste resultado é mais conclusiva nos dois primeiros eixos, que representam $50,17 \%$ da variância total dos dados. Este resultado pode ser traduzido na análise das "Coordenadas dos Indivíduos no Plano das variáveis". O eixo 1 representa o item adequação do capital. A interpretação é que uma maior imobilização total e/ou própria (IMTO e IMPR) e, conseqüentemente, um menor capital de giro (KGIR), aumenta o risco de falência. A variável binária contínua ilustrativa, relativamente à falência, está bem representada no eixo 1 , acompanhando desta forma a direção das variáveis relativas à imobilização. ${ }^{10}$

10 A variável contínua ilustrativa tem os valores calculados de suas coordenadas nos eixos, sem que ela participe do cálculo das coordenadas. Trata-se de encontrar o valor das variáveis nos indivíduos, um raciocínio próximo - a nosso juízo - ao de se interpretar os resultados de uma análise com variável binária dependente. Ver ESCOFIER \& PAGÈS (1992). 
O eixo 2 está relacionado à qualidade de ativos (variáveis INDP e PROV). Uma consulta ao Quadro 2 mostra que o sinal apresentado pela coordenada está coerente com o que se espera do modelo. A análise das coordenadas dos indivíduos no plano formado pelos dois primeiros eixos pode evidenciar que existe um banco responsável pela extensão do eixo 2. Testou-se, então, o papel do banco ADOL (ver Anexo I ), e o resultado mostrou que ainda que sua contribuição à variância seja diferenciada, o eixo se mantém quando se retira este outlier, seja no modelo com 26 variáveis, seja no modelo que nos interessa, relativo à Tabela 7 acima. $\mathrm{O}$ eixo 3 está relacionado à solvência corrente dos bancos ( $\mathrm{SOCO}$ e aos gastos administrativos $\mathrm{CADM}$ ). Maiores gastos administrativos estão relacionados à maior solvência. Novamente testou-se a importância de um banco outlier, SJOR, na formação do eixo 3. Realmente, são poucos os bancos que estão bem representados em planos que contenham este eixo, e não se pode afirmar que maiores gastos administrativos sejam indicadores de falência, o mesmo podendo ser dito sobre a relação entre Ativo Circulante Real/Passivo Circulante Real (SOCO) como previsor de falência.

O crescimento do lucro líquido entre dois períodos (CREL), que explica o eixo 4 e as variáveis de rentabilidade (MGLQ e outras), bem representadas no eixo 5 , não contribuíram para a explicação das diferenças entre bancos. Percebe-se um certo trade-off entre o crescimento dos bancos e sua rentabilidade, o que embora possa indicar a presença de comportamentos de seleção adversa, não podem ser, todavia, associados à previsão de falência.

A Figura 1, a seguir, permite visualizar o chamado primeiro plano das coordenadas. A nosso ver, este é o plano de maior interesse para os propósitos de identificar, no conjunto das 26 variáveis iniciais, aquelas que mais fortemente estão relacionadas ao risco de falência dos bancos. Percebe-se que a variável contínua ilustrativa FALE está bem representada no eixo e somente nele. Mostra também que está na direção dos bancos que faliram e bem representados neste eixo e se opondo àqueles bancos em ótima situação financeira. 


\section{FIGURA 1 - COORDENADAS DAS VARIÁVEIS NO PRIMEIRO PLANO FATORIAL}

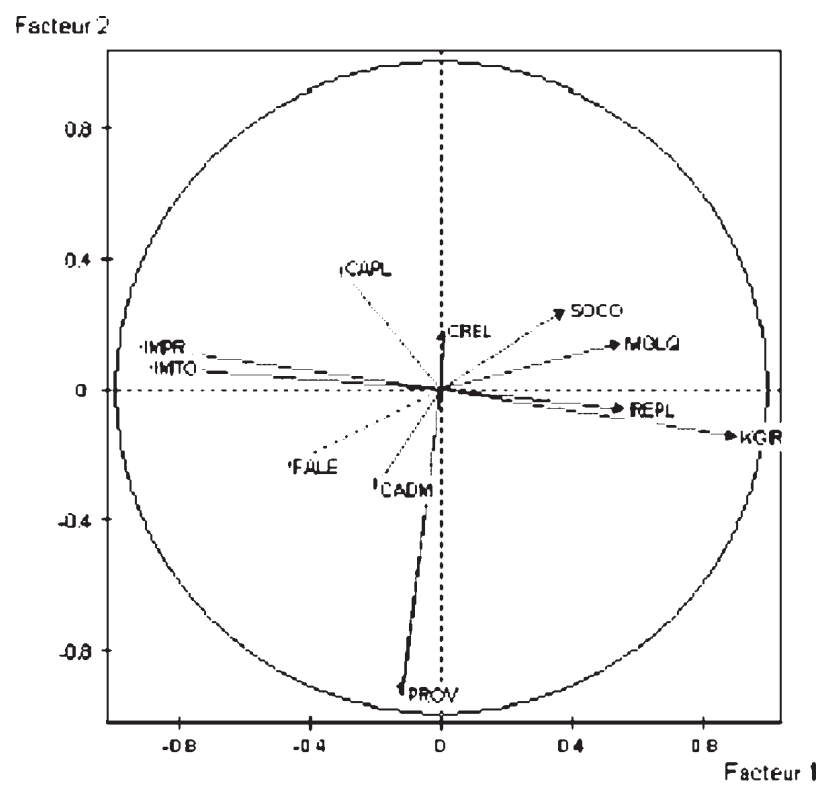

A situação dos indivíduos (bancos) aparece na Figura 2. A análise da qualidade de representação (medida pela qualidade da projeção, em co-senos quadrados) mostra, pelos rótulos, uma "fronteira de bancos falidos", que vai de OPEN até ROSA. Estes estão bem representados no plano, assim como os outliers DRAC (eixo 1), GNPP e ADOL (eixo 2). ${ }^{11}$ Esta fronteira está na direção de bancos com elevados valores nas variáveis de imobilização de capital (IMTO E IMPR), em oposição àqueles com elevado capital de giro (KGIR). Justamente neste lado oposto à fronteira estão bem representados bancos que não faliram, como mostraremos no Quadro 3.

Alguns bancos, como BFI, INVE e ATLA, estão maus representados neste plano. Na verdade, eles estão melhor representados em outros planos, os quais conceitualmente aqui não nos interessa. Por outro lado, sua situação de falência não pode ser explicada pela metodologia que estamos apresentando. Há três problemas: CACI, BMC e BMD deveriam ter problemas se o critério de imobilização do capital fosse determinante da falência, uma vez que eles estão próximos do que chamamos de fronteira de bancos falidos.

11 O Banco com rótulo ADOL não aparece na Figura 2 para facilitar a visualização dos resultados. 


\section{FIGURA 2 - REPRESENTAÇÃO DOS INDIVÍDUOS NO PRIMEIRO PLANO VETORIAL}

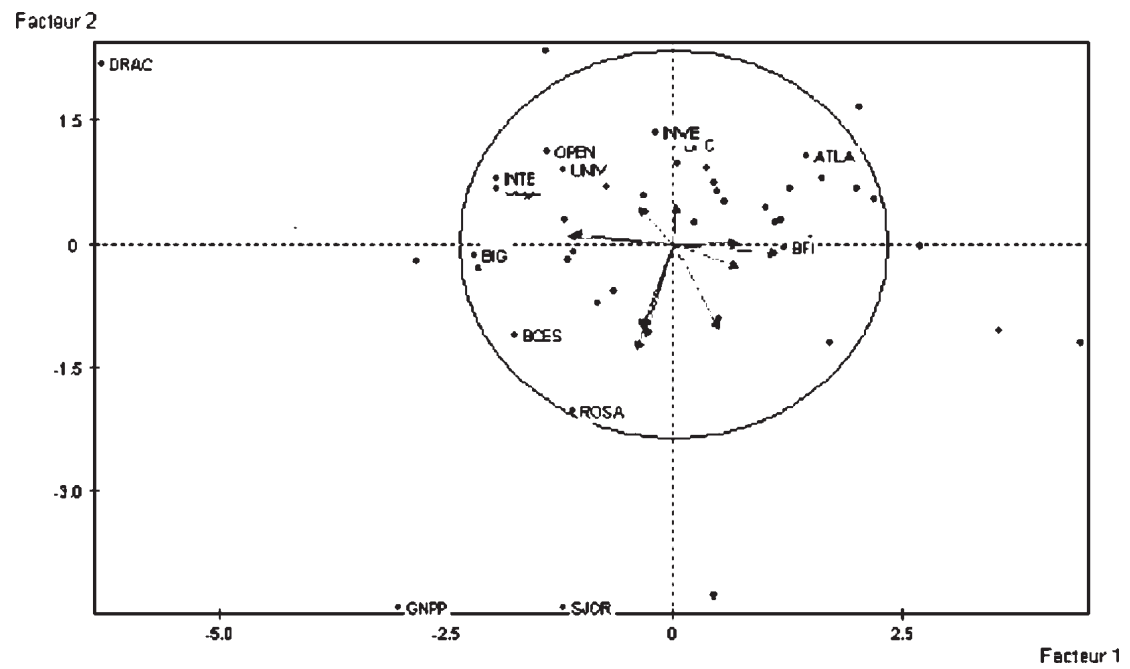

Finalmente, o modelo permite a identificação de clusters de bancos com base nos 11 indicadores apresentados no Quadro $2 .{ }^{12}$ Os resultados da aplicação do método de classificação podem ser interpretados à luz da discussão sobre os fatores determinantes da falência de bancos atacadistas. Isto significa que utilizamos os resultados apresentados nas Figuras 1 e 2 para avaliar se as classes formadas são passíveis de interpretação ou se agrupariam os indivíduos de forma que não nos ajudaria a investigar os fatores determinantes do risco de falência de bancos.

O método de classificação hierárquica nos indica que:

a) Formaram-se dois grupos de bancos de interesse para nossa interpretação, sendo que um deles agrupa os bancos que faliram. $\mathrm{O}$ outro grupo é formado principalmente por bancos com bom desempenho em relação às variáveis que mais discriminam saudáveis de falidos. O banco SUMI é um exemplo de excelente desempenho no que tange ao capital de giro, estando no extremo

12 O método utilizado inicialmente é o da formação de clusters por critério de hierarquia, o chamado método da classificação hierárquica. O algoritmo utilizado é o de Ward, que consiste em ir formando grupos de pares próximos que, em síntese, minimizam a variância dentro do grupo e aumentam a variância fora. Assim, indivíduos muito semelhantes (próximos no plano em que suas projeções são bem definidas) vão sendo agrupados. Em seguida, aplica-se o "método de partição por classes”, baseado no algoritmo de Forgy, que procura, de forma interativa, encontrar a melhor participação em classes. Ver CRIVISKY (1998). 
oposto, ao longo do eixo 1 , dos bancos que faliram, o que pode ser visto na Figura 2.

b) Dois outliers contribuíram fortemente na participação de grupos. Um deles (ADOL) se diferencia da maioria por ter um péssimo desempenho no que tange à qualidade de ativos, ou seja, nas variáveis que definem o eixo 2 da ACP (INDP e PROV, ver Quadro 2). Praticamente forma-se um grupo à parte. O outro, DRAC, embora fique no grupo dos que faliram em razão da elevada imobilização de ativos (elevados valores de IMPR, IMTO e com baixo KGIR, no Quadro 2), também é um outlier.

c) Há uma porcentagem pequena de indivíduos mal representados no primeiro plano. O melhor exemplo é o banco ATLA, que, na verdade, está mal projetado no plano formado pelos dois primeiros eixos, aquele em que a variável contínua ilustrativa FALE (variável binária que separa FALIDOS de SAUDÁVEIS) está bem representada (ver Figura 1).Também BFI, INVE e BFC estão mal representados neste plano, o que se reflete em sua posição nos clusters indicados pela distribuição hierárquica.

Tal resultado sugeriu um número maior de partições. Utilizando o método de partições em classes, já mencionado, formamos 7 e 8 partições, observando o quanto de variância interclasses era ganha à medida que iam sendo formados. Há uma regra de corte que interrompe o número de grupos quando o ganho de variância interclasses fica abaixo de um certo limite.

A separação em 8 grupos não difere essencialmente da divisão em três grupos no que tange à distinção entre FALIDOS e SAUDÁVEIS, com as exceções mencionadas acima de indivíduos que estão mal representados no plano que melhor discrimina esses grupos, que é o formado pelo eixos $1 \mathrm{e}$ 2. A formação de 8 grupos deixa cerca de $75 \%$ da variância para fora de cada grupo, quase o dobro do alcançado pela repartição em três classes, ainda em um nível aceitável, próximo a 40\%.

O Quadro 3, a seguir, resume os resultados da formação de clusters à luz dos resultados da ACP, apresentados na Figura 2, nos valores dos compo- 
nentes principais de cada indivíduo e na qualidade de sua representação em cada eixo (que permite avaliar os também a qualidade de representação nos planos formados pelos eixos, especificamente o plano formado pelos eixos 1 e 2 e 2 e 3 ).

\section{QUADRO 3 - PRINCIPAIS CARACTERÍSTICAS DO AGRUPAMEN- TO DE BANCOS E O COMPORTAMENTO DOS FALI- DOS (F) E SAUDÁVEIS (S) REPRESENTADOS NOS PLANOS FORMADOS PELOS EIXOS 1,2 E 3}

\begin{tabular}{|c|c|c|}
\hline $\begin{array}{l}\text { GRUPOS DE BANCOS } \\
\text { (clusters) }\end{array}$ & $\begin{array}{l}\text { Plano/Eixos em que estão } \\
\text { representados }\end{array}$ & Caracterização do Cluster \\
\hline 1. $A D O L(F)$. & Plano 1 e 2 : eixo 2 - outlier. & Baixíssima qualidade de ativos: Falido. \\
\hline 2. SJOR (F) e SANE (S). & $\begin{array}{l}\text { Planos } 2 \text { e 3: eixo } 3 \text { - caberia } \\
\text { investigar as causas particulares da } \\
\text { falência de SJOR e o porquê de } \\
\text { SANE ser saudável. }\end{array}$ & $\begin{array}{l}\text { Elevados custos administrativos e elevado índice de } \\
\text { solvência. Na repartição em três classes, } \\
\text { encontram-se em outra classe os bancos BOST, } \\
\text { ING e BNL, com baixos custos administrativos e } \\
\text { baixa solvência mas saudáveis, estando próximos } \\
\text { do bloco dos bancos saudáveis por critérios de } \\
\text { imobilização (adequação) e qualidade de ativos. }\end{array}$ \\
\hline $\begin{array}{l}\text { 3. SELL(F), ROSA(F), } \\
\text { BIG(F), BCES(F), } \\
\text { UNIV(F), GNPP(F), INTE } \\
\text { (F) e OPEN(F), junto com } \\
\text { os saudáveis BOSI(S), } \\
\text { CIDA(S), BCR(S), } \\
\text { RURAL(S), ARBI(S), } \\
\text { CACI(S), BMD(S) e } \\
\text { PANA(S). }\end{array}$ & $\begin{array}{l}\text { Compõe a "fronteira de falência" na } \\
\text { Figura } 2 \text {. Todos estão bem } \\
\text { representados no Plano 1,2, com } \\
\text { exceção de ROSA(F) que tem } \\
\text { problemas com qualidade de ativos } \\
\text { (INDP e PROV) e os saudáveis } \\
\text { BOSI, ARBI e CIDA que não estão } \\
\text { bem representados em nenhum } \\
\text { plano. }\end{array}$ & $\begin{array}{l}\text { Com exceção de ROSA(F), todos os outros } \\
\text { apresentaram elevados níveis de imobilização do } \\
\text { capital, alinhando-se na direção do plano de } \\
\text { falência. GNPP é o que melhor se alinhou no plano, } \\
\text { por combinar elevada imobilização e má qualidade } \\
\text { de ativos. Localizado no lado oposto do Plano } \\
\text { formado pelos eixos } 1 \text { e } 2 \text { da Figura 2, estão os } \\
\text { bancos estritamente saudáveis. Na repartição em } \\
\text { três classes eles se afastam da "fronteira de } \\
\text { falência" por estarem em outro cluster. }\end{array}$ \\
\hline 4. DRAC $(F)$ - outlier. & $\begin{array}{l}\text { Como os bancos que compõem a } \\
\text { "fronteira de falência", tem } \\
\text { elevadíssimo índice de imobilização } \\
\text { de capital. Todavia, não alinha ao } \\
\text { plano de falência (FALE da Figura 2) } \\
\text { por não ter problemas com } \\
\text { qualidade de ativos ou custos } \\
\text { administrativos elevados. }\end{array}$ & $\begin{array}{l}\text { Sua presença como outlier o coloca como separado } \\
\text { do cluster formado pela "fronteira de falência", mas } \\
\text { não muito distante delas. }\end{array}$ \\
\hline $\begin{array}{l}\text { 6. CONT(S), FENI(S), } \\
\text { SUMI(S) e ING(S). }\end{array}$ & $\begin{array}{l}\text { Cluster de bancos que se opõe } \\
\text { radicalmente à "fronteira de falência" } \\
\text { pelo alto valor do capital de giro. }\end{array}$ & $\begin{array}{l}\text { Elevado capital de giro ou pequena imobilização do } \\
\text { capital. Estão bem representados no eixo } 1 \text {, no } \\
\text { plano } 1 \text { e } 2 \text {. O plano } 1 \text { e } 3 \text { mostra que esses bancos } \\
\text { têm elevados rendimentos e solvência que os } \\
\text { diferenciam dos demais. }\end{array}$ \\
\hline $\begin{array}{l}\text { 7. FIBR(S), BMC(S), } \\
\text { VOTO(S), NORC(S), } \\
\text { BNL(S), REND(S), } \\
\text { MULT(S), ABN(S), } \\
\text { LLOY(S), CRED(S), } \\
\text { GM(S) e ATLA(F). }\end{array}$ & $\begin{array}{l}\text { Opõe-se à "fronteira de falência" da } \\
\text { Figura 2, mas de forma menos clara } \\
\text { que o cluster anterior. Ainda assim, } \\
\text { com uma maioria de bancos } \\
\text { saudáveis cuja causa está em } \\
\text { oposição à "fronteira de falência". }\end{array}$ & $\begin{array}{l}\text { Caracterizados por elevado capital de giro, com } \\
\text { exceções dos bancos VOTO e CRED que estão mal } \\
\text { representados no plano } 1 \text { e } 2 \text {. O plano } 2 \text { e } 3 \text { mostra } \\
\text { que BNL, MULT, REND e NORC se caracterizam } \\
\text { por baixos custos administrativos e rentabilidade. }\end{array}$ \\
\hline
\end{tabular}


O Quadro 3 refere-se basicamente à situação dos Falidos $(\mathrm{F})$, sendo os bancos Saudáveis $(S)$ tomados como base de comparação na análise dos grupos. O Quadro 4 refere-se aos clusters de bancos que não estão bem representados nos planos formados pelos três primeiros eixos.

\section{QUADRO 4 - PRINCIPAIS CARACTERÍSTICAS DO AGRUPAMENTO DE BANCOS E O COMPORTAMENTO DOS FALIDOS (F) E SAUDÁVEIS (S) REPRESENTADOS POR “OUTROS PLANOS”}

\begin{tabular}{|cll|}
\hline $\begin{array}{l}\text { GRUPOS DE BANCOS } \\
\text { (clusters) }\end{array}$ & \multicolumn{1}{c|}{ Plano/Eixos em que estão representados } & Caracterização do Cluster \\
\hline 5. BOST(S) e ING(S) & $\begin{array}{l}\text { Estão bem representados nos planos formados } \\
\text { pelos eixos 2 e 3 e 3 e 4. Distanciam-se portanto } \\
\text { da maioria dos bancos, mas na partição em 3 } \\
\text { classes estão no bloco dos saudáveis, apesar de } \\
\text { apresentarem elevada imobilização de capital. }\end{array}$ & $\begin{array}{l}\text { Agrupam-se pelo baixo } \\
\text { custo administrativo, baixa } \\
\text { solvência e principalmente } \\
\text { pelo rápido crescimento } \\
\text { (CREL). }\end{array}$ \\
$\begin{array}{lll}\text { 8. BFC (F), INVE(F), } \\
\text { BFI(F), SOGE(S), }\end{array}$ & $\begin{array}{l}\text { Não há uma unidade de representação deste } \\
\text { DIBE(S), INAT(S), }\end{array}$ & \\
VOTO(S), BBA(S), & & \\
FIAT(S) e BMG(S) & & \\
\hline
\end{tabular}

A análise dos quadros acima mostra que, grosso modo, a separação em 3 classes foi eficiente para separar falidos e saudáveis. A retirada do outlier ADOL permite a formação de 4 classes que estão ainda melhor definidas do ponto de vista da identificação entre Falidos e Saudáveis, diminuindo os problemas apresentados no cluster 8, do Quadro 4. Mantivemos a análise completa justamente para evidenciar os problemas que surgem neste tipo de análise exploratória.

$\mathrm{O}$ resultado obtido apresentou as seguintes qualidades do ponto de vista de um instrumento de suporte às técnicas de early warning:

a) foram identificadas as principais variáveis determinantes da falência: variáveis associadas à imobilização de capital e qualidade de ativos;

b) foram identificados os bancos que se mantiveram saudáveis, apesar de aparentemente compartilharem a situação dos falidos. Em alguns casos, a investigação do papel de outro grupo de variáveis permitiu identificar a razão, como, por exemplo, no caso do banco BOST, que apresenta elevada imobilização, como os falidos, mas elevado 
rendimento, rápido crescimento de ativos e baixos custos administrativos;

c) foram identificados os outliers, principalmente aqueles casos em que a situação foi extremamente grave no sentido das causas da falência.

A seguir, passamos ao modelo de previsão de falência propriamente dito, a saber, o modelo logit utilizando as variáveis em parte indicadas pelo uso da ACP. Mais precisamente, deseja-se analisar a importância das variáveis que representam a imobilização de capital como determinantes da falência, assim como aquelas relacionadas ao eixo 2: qualidade de ativos. Testa-se também a importância das variáveis relacionadas à solvência. Percebeu-se que, em muitas situações, os bancos solventes se diferenciavam por seus baixos custos administrativos, o que também deveria ser testado pelo modelo. ${ }^{13}$

Iniciamos por um modelo mais amplo, contendo as variáveis definidoras dos três primeiros eixos definidos pela ACP. A seguir, utilizando os testes de qualidade de ajuste (valor médio da função de verossimilhança e o valor esperado do ajuste em 50\%), reduziu-se o modelo para duas variáveis, KGIR e CINT, sem contudo obter-se grandes mudanças no resultado. O resultado do modelo logit foi altamente satisfatório, mostrando que ambas as variáveis foram bastante significativas na explicação da falência dos bancos atacadistas.

TABELA 8 - RESULTADO DO MODELO LOGIT

\begin{tabular}{lrrrc}
\hline Variável & Coeficiente & Erro Padrão & Estatística Z & Nível de Significância \\
\hline KGIR & $-0,03165$ & 0,015625 & $-2,02551$ & 0,0428 \\
CINT & 0,012 & 0,00371 & 3,23240 & 0,0012 \\
SOCO & $-0,015161$ & 0,0071 & -2.12998 & 0.0332 \\
\hline
\end{tabular}

13 O uso dos componentes principais para a análise do modelo logit foi consistente com os resultados dos modelos que serão apresentados a seguir. Todavia, o ajuste foi substancialmente melhor com o uso de variáveis que definem a formação dos eixos do que com o uso das variáveis relativas aos três primeiros eixos, $\mathrm{Cla}$ C3. Observou-se também que a variável CINT expressou melhor o papel dos custos no modelo logit que a variável CADM, utilizada na ACP. 


\begin{tabular}{lcccccccc}
\hline \multirow{2}{*}{ Variável: } & \multicolumn{3}{c}{ Média: } & & \multicolumn{3}{c}{ Desvio Padrão: } \\
\cline { 2 - 3 } \cline { 7 - 9 } & AS & AF & Total: & AS & AF & Total: \\
\hline CINT & 60.45424 & 869.7153 & 313.3483 & & 82.10010 & 1882.716 & 1097.328 \\
KGIR & 51.05606 & 30.02667 & 44.48438 & & 29.75910 & 29.14745 & 30.87170 \\
SOCO & 112.5376 & 106.7087 & 110.7160 & & 17.49349 & 23.36023 & 19.45147 \\
\hline
\end{tabular}

Nota: AF - Atacadista falido; AS - Atacadista saudável.

Os sinais dos coeficientes mostraram-se conforme intuitivamente esperado: quanto maior o custo de intermediação e menor o capital de giro (ou seja, maior a imobilização do capital), maiores as chances de um banco atacadista quebrar. Também a variável relacionada à solvência corrente (SOCO) apresentou o sinal adequado, refletindo o fato de que quanto maior seu nível, menor tende a tornar-se o risco de falência. De fato, as médias dessas variáveis mostraram-se significativamente diferentes para os dois grupos (maior custo de intermediação médio e menor capital de giro médio para os AF). Isso contribuiu para a eficácia do modelo.

Foi calculada para cada banco sua probabilidade de falência. Essa probabilidade foi comparada com um valor de corte igual a 0,5 . Se esse valor fosse superior a 0,5 , o banco seria classificado como frágil, caso contrário, como saudável. Novamente o modelo mostrou-se eficaz, classificando corretamente grande parte dos bancos, como revela a Tabela 9.

TABELA 9 - CLASSIFICAÇÃO DOS BANCOS PELO MODELO LOGIT ${ }^{*}$

\begin{tabular}{lrrr}
\hline Tipo/classificação & \multicolumn{1}{c}{ AS } & \multicolumn{1}{c}{ AF } & \multicolumn{1}{c}{ Total: } \\
\hline Bem classificado: & $96,97 \%$ & $80,0 \%$ & $91,67 \%$ \\
Erro tipo I & - & $20,0 \%(3)$ & $6.25 \%(3)$ \\
Erro tipo II & $3.03 \%(1)$ & - & $2,08 \%(1)$ \\
Total & $100 \%(33)$ & $100 \%(15)$ & $100 \%(48)$ \\
\hline
\end{tabular}

${ }^{*}$ ): A freqüência dos bancos está entre parênteses. 
O modelo logit classificou corretamente $96,97 \%$ dos AS e $80,0 \%$ dos AF, num total de $91,7 \%$ dos bancos. O erro tipo I (classificar o banco como saudável incorretamente) ocorreu em apenas 3 (6,25\%) dos casos. O erro tipo II - classificar o banco como frágil incorretamente - foi ainda menor $(3,03 \%)$. Portanto, o modelo logit mostrou-se eficaz, tanto pelo alto poder explicativo das variáveis utilizadas quanto por classificar corretamente a maior parte dos bancos.

Vale realçar que, neste trabalho, a análise de ACP foi tomada como um passo intermediário da estimativa do modelo logit, funcionando como um modelo de pré-seleção de variáveis. Trata-se de uma análise exploratória que acreditamos ser útil para perceber como a probabilidade de falência está mais fortemente correlacionada a um determinado feixe de variáveis do que a outros e como isto pode ser associado ao comportamento dos indivíduos. Desta forma, trata-se de um modelo complementar que inclusive motiva a análise mais cuidadosa de outliers $e$ das fontes de erros que classificamos como de tipo I e II, seguindo a literatura.

Consideramos que esta metodologia ajuda a superar as críticas de que existe uma dificuldade crescente no uso de modelos de previsão de risco diante da instabilidade atual. Também fica claro que o uso da ACP sofre a limitação de partir de uma separação já ocorrida e conhecida entre falidos e saudáveis. O modelo do tipo logit, por seu turno, dá indicações, passíveis de futuros testes, sobre o papel das variáveis relacionadas à imobilização de capital, à qualidade de ativos, à solvência e custos na trajetória dos bancos.

\section{CONSIDERAÇÕES FINAIS}

Antes de compararmos os resultados dos testes realizados nesse trabalho com os dos outros dois estudos aqui mencionados (JANOT, 2001 e ROCHA, 1999), cumpre lembrar que se trataram de análises com modelos, amostras de bancos e indicadores econômico-financeiros distintos, além de utilizarem bases de dados de períodos diferentes. 
De qualquer modo, além dos fatores citados acima, o fato de se estar trabalhando aqui apenas com bancos atacadistas influenciou decisivamente na diferença entre os resultados desses trabalhos. Portanto, a hipótese de que os bancos atacadistas possuem microdeterminantes de falência peculiares está correta ou, pelo menos, a mesma não pode ser rejeitada. Fatores que, de acordo com trabalhos anteriores, se mostraram relevantes na determinação da crise bancária brasileira não foram revelados como importantes na determinação da falência dos bancos atacadistas brasileiros pelo teste aqui realizado. Ao mesmo tempo, fatores apontados como importantes na explicação das quebras ocorridas no setor bancário atacadista não foram levantados pelos trabalhos anteriores.

Essas diferenças podem ser creditadas às características estruturais dos bancos atacadistas. Conforme verificado, a qualidade dos créditos não foi um fator apontado como relevante na determinação da falência dos bancos atacadistas, uma vez que as operações de crédito não são a principal rubrica ativa dos bancos atacadistas. Convém observar que esse fator também não foi considerado relevante nos trabalhos de Janot (2001) e Rocha (1999).

O trabalho de Janot (2001) apontou uma baixa proporção de ativos líquidos no total de ativos como um microfundamento importante para explicar as falências ocorridas no sistema bancário brasileiro. A variável mais próxima desse indicador no estudo aqui realizado é a cobertura voluntária (ver Quadro 2), e a mesma não foi levantada como um microfundamento de falência relevante no caso dos bancos atacadistas. Isto pode sugerir que, por possuírem uma estrutura passiva de prazo mais longo que a dos varejistas, os bancos atacadistas não precisam formar uma estrutura ativa de prazo mais curto para evitar o descasamento de prazos e suprir os recursos demandados pelos depositantes numa eventual fuga de depósitos. No entanto, tal afirmação não pode ser tão contundente, já que uma baixa solvência corrente foi associada, pelo teste logit, a uma maior probabilidade de falência, sugerindo que uma baixa proporção de ativos líquidos é prejudicial inclusive para bancos de atacado. 
O trabalho de Janot (2001) também apontou como relevante um elevado nível de gastos administrativos. No caso dos bancos atacadistas, os custos considerados relevantes na determinação de falência não foram os administrativos, mas sim os de intermediação. De fato, os bancos atacadistas operam com uma estrutura mais enxuta e é de se esperar que os mesmos não tenham muitos problemas com custos administrativos. Contudo, por possuírem uma estrutura passiva de prazo mais longo, seus custos de intermediação são maiores, aparecendo como relevantes na determinação da quebra dos bancos atacadistas.

Outro fator apontado como relevante na explicação da falência dos bancos atacadistas foi a alta imobilização do capital. Os bancos atacadistas, de uma forma geral, possuem baixa imobilização do capital. Isso sugere que um elevado nível de capital disponível para aplicações constitui-se em variável estratégica para os bancos atacadistas. Um banco atacadista que não possua um capital de giro suficiente é obrigado a captar recursos no mercado. Mas, como aponta Rocha (1999), os bancos menores - tamanho no qual se enquadra a maioria dos bancos atacadistas - captam por meio de instrumentos de maior risco. Portanto, os bancos atacadistas com baixo capital de giro foram forçados a se alavancar, o que acabou por prejudicar seu desempenho. Isto está condizente com uma das conclusões apontadas por Rocha (1999), segundo a qual os bancos pequenos com maior alavancagem se fragilizaram.

No caso desse texto, buscamos mostrar que características estruturais dos bancos devem ser levadas em conta quando se pretende identificar microdeterminantes de falência bancária e, portanto, também quando se for pensar nas estratégias adequadas para se evitar a fragilização bancária.

\section{BIBLIOGRAFIA}

ALEXANDRE, M. Microfundamentos de falência de bancos atacadistas: a experiência brasileira nos anos 90. 2001. Dissertação (Mestrado), Universidade Estadual de Campinas. Dezembro.

BAER, W.; NAZMI, N. Privatization and restructuring of banks in Brazil. The Quarterly Review of Economics and Finance. North-Holland, 2000. 
CANUTO, O.; LIMA, G. T. Crises bancárias, redes de segurança financeira e currency boards em economias emergentes. Revista Econômica do Nordeste, v. 30. Edição especial. Dezembro 1999.

CARVALHO, F. C. de. Price stability and banking sector distress in Brazil after 1994. Rio de Janeiro: UFRJ, Instituto de Economia, Texto para Discussão no 388, Março 1996.

CLAESSENS, S.; KLINGEBIEL, D.; LAEVEN, L. Financial restructuring in banking and corporate sector crises: what policies to pursue? NBERConference on Management of Currency Crises. Monterrey, 28 a 31 de Março 2001.

COSTA, S. G.; GONÇALVES, P. C. Estratégias corretas. Conjuntura Econômica, Junho 1997.

CRIVISKY, E. Presentación del analisis de componentes principales. Programa Presta Universidad Libre de Bruxelles, 1998, 58p. Mimeografado.

DE JUAN, A. The roots of banking crises: microeconomic issues. In: HAUSMANN, R.; ROJAS-SUÁREZ, L, Banking crises in Latin America. Washington: Inter-American Development Bank, 1996.

DEMIRGÜÇ-KUNT, A.; DETRAGIACHE, E. The determinants of banking crises: evidence from developing and developed countries. IMF Working Paper, September 1997.

ESCOFIER, B.; PAGÈS, J. Análisis factoriales simples y multiples. Bilbao: Ed. Universidad del Pais Vasco, Dunod, 1992, 285p.

GAVIN, M.; HAUSMANN, R. The roots of banking crises: macroeconomic issues. In: HAUSMANN, R.; ROJAS-SUÁREZ, L., op. cit., 1996.

GOLDSTEIN, M.; TURNER, P. Banking crises in emerging economies: origins and policy options. BIS Economic Papers, n. 46, October 1996.

HAUSMANN, R.; ROJAS-SUÁREZ, L. Conclusions and the policy debate. In: HAUSMANN, R.; ROJAS-SUÁREZ, L. , op. cit., 1996.

JANOT, M. Modelos de previsão de insolvência bancária no Brasil. Trabalhos para Discussão no 13. Brasília: Banco Central do Brasil, 2001.

KAGEYAMA, A.; SILVEIRA, J. M. F. J. da. Agricultura e questão regional. Revista Brasileira de Economia e Sociologia Rural, v. 4, n. 1, p. 332, 1997.

LOYOLA, G.; BARROS, J. R. M. de, PARENTE, P. P.; ALMEIDA JR., M. F. A. A reestruturação em curso dos bancos públicos. Jornal $G a-$ zeta Mercantil, 25 de agosto de 1997.

MIOTTI, L.; PLIHON, D. Liberalisation financiere, speculation et crises bancaires. Colloque "Convergence des systèmes financiers et dynamique finance - industrie”. Université Paris - Nord, 28 et 29 juin, 1999. 
ROCHA, F. Previsão de falência bancária: um modelo de risco proporcional. Pesquisa e Planejamento Econômico, Rio de Janeiro, v. 29, n. 1, Abril 1999.

SACHS, J. Alternative approaches to financial crises in emerging makets. Revista de Economia Política, São Paulo, v. 16, n, 2. abril-junho 1996.

STIGLITZ, J. E.; WEISS, A. Credit rationing in markets with imperfect competition. American Economic Review, n. 73, 1981.

VON DOELLINGER, C. Reordenação do sistema financeiro. In: Perspectivas da Economia Brasileira 1992. Brasília: IPEA, 1991.

ANEXO I - AMOSTRA DE BANCOS UTILIZADA

1. BANCOS ATACADISTAS LIQUIDADOS PELO BANCO CENTRAL (EM REGIME DE LIQUIDAÇÃO EXTRAJUDICIAL):

\begin{tabular}{lcc}
\hline Banco: & Data da Liquidação: & Sigla: \\
\hline Banco Adolpho Oliveira & 14.11 .94 & ADOL \\
Banco Seller & 18.11 .94 & SELL \\
Banco Atlantis & 21.11 .94 & ATLA \\
Banco Open & 23.01 .95 & OPEN \\
Banco Comercial Bancesa S.A. & 13.02 .95 & BCES \\
Banco São Jorge & 01.03 .95 & SJOR \\
Banco Rosa & 03.03 .95 & ROSA \\
Banco Irmão Guimarães S.A. & 25.09 .95 & BIG \\
BFC Banco S.A. & 04.12 .95 & BFC \\
Banco GNPP S.A. & 05.12 .95 & GNPP \\
Banco Investcorp S.A. & 05.12 .95 & INVE \\
Banco Dracma S.A. & 21.03 .96 & DRAC \\
BFI & 17.04 .96 & BFI \\
Banco Universal S.A. & 20.06 .96 & UNIV \\
Banco Interunion S.A. & 30.12 .96 & INTE \\
\hline
\end{tabular}

Fonte: Conjuntura Econômica e Austin Asis. 


\section{BANCOS ATACADISTAS SAUDÁVEIS INTEGRANTES DA} AMOSTRA:

\begin{tabular}{llllll}
\hline Nome: & Sigla: & Nome: & Sigla: & Nome: & Sigla: \\
\hline Bozano Simonsen & BOSI & Banco Arbi & ARBI & Inter-Atlântico & INAT \\
Votorantim & VOTO & BBA Creditanstalt & BBA & Investcred & INCR \\
Lloyds Bank & LLOY & BMC & BMC & Norchem & NORC \\
ABN Amro Bank & ABN & BMD & BMD & Panamericano & PANA \\
Bank of Boston & BOST & BMG & BMG & Rendimento & REND \\
Bancocidade & CIDA & BNL & BNL & Santos Neve & SANE \\
Chase Maniatan & CHAS & Banco Cacique & CACl & Sogeral & SOGE \\
Banco Rural & RURA & Credibanco & CRED & Sumitomo & SUMI \\
Banco Fiat & FIAT & Banco Dibens & DIBE & BCR & BCR \\
Banco Fibra & FIBR & Banco Fenícia & FENI & Continental & CONT \\
Multiplic & MULT & General Motors & GM & ING Bank & ING \\
\hline
\end{tabular}

\section{ANEXO II - OS BANCOS OUTLIERS}

Apesar de não apresentar problemas com capital de giro, o banco Adolpho Oliveira apresentou uma solvência corrente muita baixa e uma elevada taxa de inadimplência. O banco Seller destacou-se pelo nível de capital de giro extremamente baixo. Sua rentabilidade relativamente elevada pode ser um sinal de envolvimento com atividades de alto risco. O banco Atlantis apresentou custos de intermediação significativamente elevados, exibindo, no entanto, alto nível de capital de giro. O banco São Jorge apresentou alta taxa de inadimplência, altos custos administrativos e elevados prejuízos. $\mathrm{O}$ banco Rosa destaca-se pelos custos de intermediação extremamente elevados e pelas baixas taxas de crescimento. O banco BIG apresentou elevados prejuízos e baixas taxas de crescimento. O banco GNPP exibiu alta taxa de inadimplência. O banco Investcorp exibiu taxas de crescimento muito baixas. O banco Dracma apresentou capital de giro negativo (ou seja, seu ativo permanente é superior a seu patrimônio líquido), prejuízos elevados e altas taxas de crescimento, indicando uma superexpansão por parte desse 
banco. O BFI apresentou altas taxas de rentabilidade (sugerindo envolvimento em atividades especulativas) e de crescimento (sugerindo superexpansão). Por fim, o banco Interunion exibiu altos custos de intermediação e elevado prejuízo.

(Recebido em outubro de 2002. Aceito para publicação em abril de 2003). 